\title{
Pharmacokinetics of Tinidazole in Chinese subjects: Comparison of Mongolian, Korean, Hui, Uighur and Han nationalities
}

\author{
Xin-Yu Chang ${ }^{1}$, Tao Guo ${ }^{2}$, Dong-Ya Xia ${ }^{2}$ \\ ${ }^{1}$ School of Pharmacy, Shenyang Pharmaceutical University, Shenyang, China; ${ }^{2}$ Dept. of Pharmacy, Shenyang North \\ Hospital, Shenyang, China.
}

Received, October 27, 2008; Revised, February 22, 2009; Accepted, July 8, 2009; Published, July 29, 2009

\begin{abstract}
Purpose. This study investigated the pharmacokinetics of tinidazole in subjects of five different Chinese nationalities (Han, Mongolian, Korean, Hui, and Uighur). Methods. Fifty healthy subjects (five male and five female of each nationality) were recruited for the study, and each received $1 \mathrm{~g}$ tinidazole. A total of 14 blood samples were collected over a 72-hour period after administration. Results. Pharmacokinetic profiles, including area under the curve from time zero to infinity $\left(\mathrm{AUC}_{0 \text {-inf }}\right)$, peak plasma concentration $\left(\mathrm{C}_{\max }\right)$, time to reach $\mathrm{C}_{\max }\left(\mathrm{t}_{\max }\right)$, oral clearance $(\mathrm{CL} / \mathrm{F})$, elimination rate constant $\left(\mathrm{K}_{\mathrm{e}}\right)$, and elimination half-life $\left(\mathrm{t}_{1 / 2}\right)$, were determined following a single oral dose of tinidazole. The respective pharmacokinetic properties of Han, Mongolian, Korean, Hui, and Uighur nationalities were: half-life (h): $16.94 \pm 2.40,16.40 \pm 1.79,16.63 \pm 1.82$, $16.81 \pm 1.56,14.34 \pm 1.92 ; \mathrm{C}_{\max }(\mu \mathrm{g} / \mathrm{mL}): 19.04 \pm 2.42,19.22 \pm 4.93,20.83 \pm 3.33,20.25 \pm 4.05,18.81 \pm 3.10$; AUC0$\inf (\mathrm{h} \cdot \mu \mathrm{g} / \mathrm{mL}): 483.13 \pm 65.65,479.70 \pm 99.74,511.07 \pm 53.47,514.25 \pm 130.78,388.58 \pm 37.37$. The $\mathrm{t}_{1 / 2}$ and $\mathrm{AUC}_{0 \text {-inf }}$ of Uighur subjects were significantly lower $(p=0.023,0.011)$ and the $C L / F$ and $K_{e}$ were significantly higher $(p$ $=0.003,0.013)$ than those of other nationalities. After normalization by weight, the differences in $\mathrm{AUC}_{0 \text {-inf }}$ and $\mathrm{CL} / \mathrm{F}$ between Uigur subjects and those of other races were still significant. Conclusions. The results indicate that ethnicity had significant impact on the pharmacokinetics of tinidazole after a single oral dose in healthy volunteers of different nationalities in China.
\end{abstract}

\section{INTRODUCTION}

Tinidazole, a potent nitromidazole compound, acts against pathogenic protozoa and a wide range of clinically significant anaerobic bacteria (1-3). The drug has been useful in preventing infections after gynecological surgery, colorectal surgery, and oral surgery (4-7). Tinidazole is widely distributed into tissues, including muscle, the gastrointestinal tract, the gallbladder, and male and female reproductive organs, and only $12 \%$ binds to plasma protein ( 8 10). In humans, elimination of tinidazole follows first-order kinetics, and $63 \%$ of a dose of tinidazole is metabolized in the liver, $25 \%$ in the renal system and $12 \%$ in the biliary (8). In vitro studies suggest it is metabolized primarily by the CYP3A4 isozyme $(77 \%)$ and to a lesser extent by CYP2B6 (12\%) $(11,12)$.

China is a multiracial country with significant disparities in genetics, physiology, pathology, eating habits, and living environments between races that may contribute to interethnic differences in drug responses. For example, ciprofloxacin halflife is considerably longer in Han compared to
Uighur and Kazak nationalities. The metabolism of antipyrine also differs significantly between Tibetan and Han healthy volunteers: clearance of antipyrine is increased by $20 \%$ in Tibetan volunteers (13-15). Given that multiple cytochrome systems are involved in the metabolism of tinidazole and potential ethnic differences in polymorphisms of these isozymes may exist, ethnic differences in the metabolism and clinical effects of tinidazole are possible. Accordingly, providing the same instructions for the use of clinical medications to different nations is not optimal and pharmacokinetic studies among different nationalities could minimize such therapeutic risks and improve efficacy and safety of the medication.

Until recently, there were few published reports regarding differences in the pharmacokinetics of tinidazole between various racial groups. The purpose of this study was to determine the pharmacokinetics of oral tinidazole in

Correspondence Author: Pro. Tao Guo, Department of Pharmacy, Shenyang North Hospital, No.83, Wenhua Road, Shenyang, Liaoning, China; sy_guotao@263.net 
healthy Han, Mongolia, Korean, Hui and Uighur subjects in China, and to identify ethnic differences among these Chinese nationalities. To our knowledge, this is the first study evaluating ethnic factors affecting the pharmacokinetics of tinidazole across multiple Chinese nationalities.

\section{METHODS}

\section{Subject selection}

Fifty healthy subjects from five different nationalities in China (Han, Mongolia, Korean, Hui, and Uighur) were recruited for the study. Each group included five male and five female subjects between 19 to 25 years of age. The ethnicity was defined as individuals who were descendants of at least three generations of the respective heredities.

All subjects were in good health as judged on the basis of history, physical examination and blood examination, including complete blood count, renal function, and liver function tests. None had a history of cardiovascular, renal, hepatic, hematological or other diseases that could affect the absorption, distribution, metabolism, or excretion of the study drug.

Written informed consent was obtained from the subjects after explanation of the purpose, procedures, and risks of the study. Institutional and ethics approval was obtained from the Shenyang North Hospital before commencement of the study. All studies were carried out in accordance with the Declaration of Helsinki.

\section{Study Design}

An open-label, single-dose study was conducted with a group of healthy Chinese subjects from five different nationalities (Han, Mongolian, Korean, Hui, and Uighur). After an overnight fast, each subject received a single oral dose of $1 \mathrm{~g}$ tinidazole tablet, unchewed and swallowed whole, with 240 $\mathrm{ml}$ of water. The medication given was sourced from the same pharmaceutical manufacturer (hence with equal bioavailability). An intravenous catheter was inserted into one forearm vein for blood collection. Blood samples $(5 \mathrm{~mL})$ were collected into test tubes containing heparin predoses at 0.25 , $0.5,1,1.5,2,3,4,8,12,24,36,48,72 \mathrm{~h}$ after a single oral dose, and then centrifuged at $3500 \mathrm{r} / \mathrm{min}$ for 10 minutes. The blood plasma was transferred to a labeled tube and frozen immediately at approximately $-20^{\circ} \mathrm{C}$ to await assay.

The participants were not allowed to lie down or sleep for the first 3 hours after administration. During the study period, standardized meals were served 12 hours prior to dosing and at 4 and 10 hours after dosing. Moreover, the subjects were instructed to avoid any other drugs, including alcohol, caffeine or nicotine, for two weeks before the study and during the days of the study. Symptoms and adverse drug reactions were recorded throughout the study period. Blood collection protocols were the same in all studies.

\section{Sample Analysis}

A simple, fast, selective, accurate and precise highperformance liquid chromatographic method coupled with an ultraviolet detector was developed for the determination of tinidazole concentrations in human plasma (16). The plasma samples of all subjects were sent to the same laboratory (Department of Pharmacy, Shenyang North Hospital) to standardize the assay methodology for tinidazole. Metronidazole was employed as the internal standard. Protein precipitation using methanol was employed. A lower limit of quantification of $0.02 \mu \mathrm{g} / \mathrm{mL}$ was achieved. QC samples were assayed with each batch of samples. The results of the QC samples were used to assess the day-to-day performance of the assay. Raw data from each subject were used to obtain the individual pharmacokinetic parameters.

\section{Pharmacokinetic Analysis}

Estimates of pharmacokinetic parameters of tinidazole, such as elimination rate constant $\left(\mathrm{K}_{\mathrm{e}}\right)$, the elimination half-life $\left(\mathrm{t}_{1 / 2}\right)$, oral clearance $(\mathrm{CL} / \mathrm{F})$, and oral volume of distribution $(\mathrm{V} / \mathrm{F})$, were obtained from DAS software (17). Peak plasma concentrations $\left(\mathrm{C}_{\max }\right)$ and time to reach $\mathrm{C}_{\max }\left(\mathrm{t}_{\max }\right)$ were obtained directly by inspection of the individual concentration-time data, and the area under the plasma concentration-time curve from time zero to the time of the last quantifiable concentration $\left(\mathrm{AUC}_{0-\mathrm{t}}\right)$ was calculated using the trapezoidal rule.

\section{Statistical Analysis}

The pharmacokinetic parameters of Han subjects 
were compared with those data obtained from Mongolian, Korean, Hui, and Uighur subjects by the method of multivariate analysis of variance with a general linear model in SPSS (18). The dependent variables were race and gender. Scheffe tests were used for Post Hoc multiple comparisons and $\mathrm{P}<$ 0.05 was considered significant. Where necessary, analysis of covariates was included to control for weight. A nonparametric rank test was used to compare $T_{\max }$ and $t_{1 / 2}$ values using the SPSS software package.

\section{RESULTS}

\section{Demographic Characteristics}

All fifty subjects (10 Han, 10 Mongolian, 10 Korean, 10 Hui, and 10 Uighur) completed the study period. Their demographic characteristics are summarized in Table 1. No significant differences were found in the age, weight and height scores among these races using examination of univariate analyses (one-way ANOVA) (19).

\section{Pharmacokinetic Results and Ethnic Comparisons}

The mean plasma concentration versus time curves of the five different nationalities for normal and semi-logarithmic coordinates are shown in Figure $1 \mathrm{a}$ and $1 \mathrm{~b}$, respectively. Mean plasma concentration versus time profiles were similar for Han, Mongolian, Korean and Hui groups. The concentrations of the Uighur group were slightly lower than others. The $\mathrm{C}_{\max }$ values for the entire group were between $18.81 \pm 3.10 \mu \mathrm{g} / \mathrm{mL}$ (Uighur) and $20.83 \pm 3.33 \mu \mathrm{g} / \mathrm{mL}$ (Korean), and no statistically significant differences of $\mathrm{C}_{\max }$ were found among these nationalities.

The $\mathrm{C}_{\max }, \mathrm{T}_{\max }, \mathrm{t}_{1 / 2}, \mathrm{~K}_{\mathrm{e}}, \mathrm{V} / \mathrm{F}, \mathrm{CL} / \mathrm{F}, \mathrm{AUC}_{0-\mathrm{t}}$ , $\mathrm{AUC}_{0 \text {-inf }}$ values of the five different nationalities (Han, Mongolian, Korean, Hui, and Uighur) after single-dose oral administration of $1 \mathrm{~g}$ of tinidazole are shown in Table 2. The $\mathrm{t}_{1 / 2}, \mathrm{CL} / \mathrm{F}$ and $\mathrm{AUC}_{0 \text {-inf }}$ values for the entire group were between $14.34 \pm 1.92$ (Uighur) and $16.94 \pm 2.40$ (Han), $1.98 \pm 0.22$ (Korean) and 2.59 \pm 0.24 (Uighur), and $388.58 \pm 37.37 \mathrm{~h} \cdot \mu \mathrm{g} / \mathrm{mL}$ (Uighur) and514.25 \pm 130.78 $\mathrm{h} \cdot \mu \mathrm{g} / \mathrm{mL}$ (Hui). The $\mathrm{t}_{1 / 2}$ and $\mathrm{AUC}_{0 \text {-inf }}$ for the Uighur group were significantly $(\mathrm{p}=0.023,0.011)$ lower and $\mathrm{CL} / \mathrm{F}$ and $\mathrm{K}_{\mathrm{e}}$ were significantly $(\mathrm{p}=0.003$, 0.013) higher than those of other nationalities (Han, Mongolian, Korean, and Hui) as determined by the method of multivariate analysis of variance with a general linear model in SPSS. The differences in $\mathrm{AUC}_{0 \text {-inf }}$ and $\mathrm{CL} / \mathrm{F}$ between Uighur and other nationalities were still significant after normalization by weight. The clearance of tinidazole in the Uighur group increased $20 \%$, and $\mathrm{AUC}_{0 \text {-inf }}$ in the Uighur group decreased $22 \%$ more than those of other nationalities. Maximal concentrations of tinidazole were observed at approximately $2 \mathrm{~h}$ after dose. Other parameters are presented in Table 2.
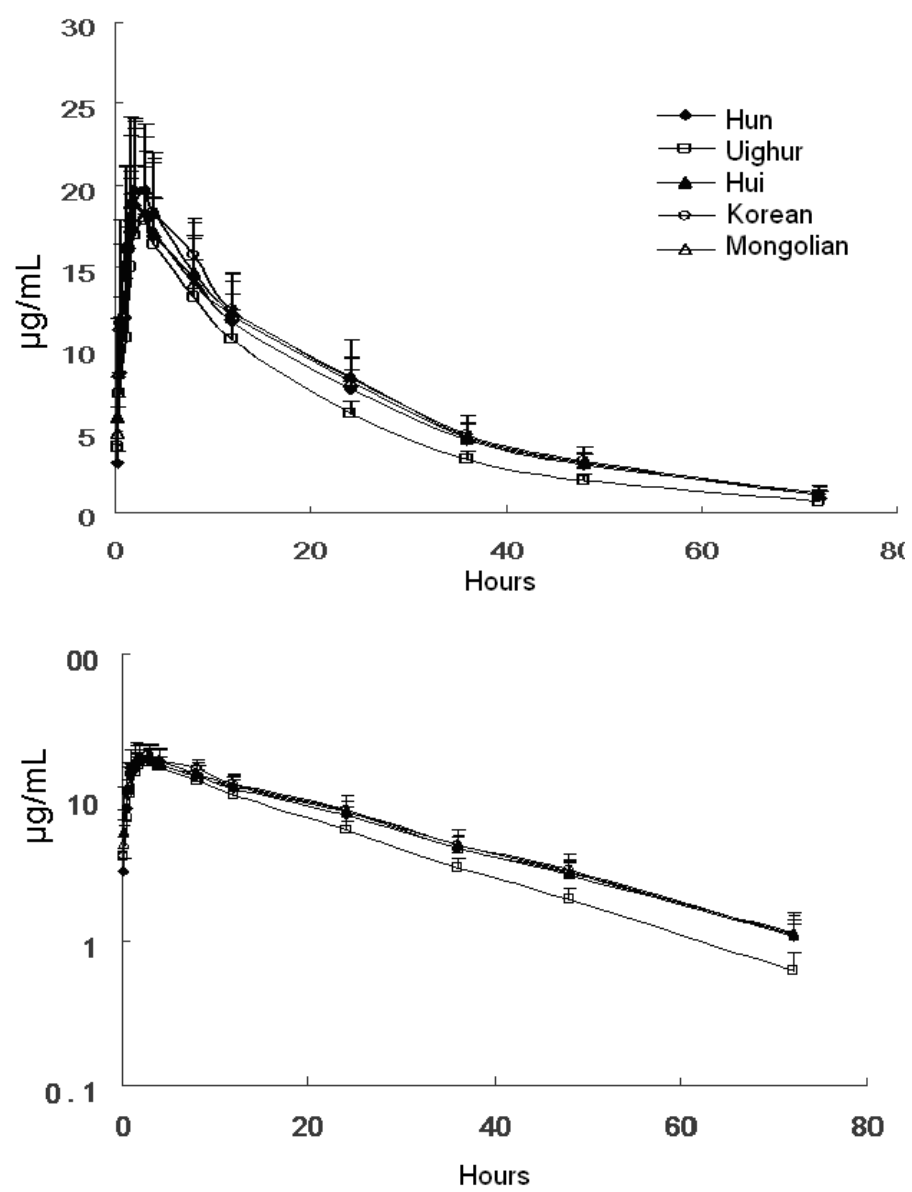

Figure 1. Mean plasma concentration verse time curves of tinidazole in healthy subjects of Han, Mongolian, Korean, Hui, and Uighur descent after a single $1 \mathrm{~g}$ administration of tinidazole. The bottom panel represents a semi-logarithm of the data. 
Table 1. Demographic Characteristics

\begin{tabular}{llllll}
\hline & $\begin{array}{l}\text { Han } \\
(\mathrm{n}=10)\end{array}$ & $\begin{array}{l}\text { Mongolia } \\
(\mathrm{n}=10)\end{array}$ & $\begin{array}{l}\text { Korean } \\
(\mathrm{n}=10)\end{array}$ & $\begin{array}{l}\text { Hui } \\
(\mathrm{n}=10)\end{array}$ & $\begin{array}{l}\text { Uighur } \\
(\mathrm{n}=10)\end{array}$ \\
\hline Gender & $5 \mathrm{~F}, 5 \mathrm{M}$ & $5 \mathrm{~F}, 5 \mathrm{M}$ & $5 \mathrm{~F}, 5 \mathrm{M}$ & $5 \mathrm{~F}, 5 \mathrm{M}$ & $5 \mathrm{~F}, 5 \mathrm{M}$ \\
Height $(\mathrm{cm})$ & $164.4 \pm 5.2$ & $163 \pm 9.6$ & $166.2 \pm 6.0$ & $165.3 \pm 9.0$ & $167.9 \pm 6.0$ \\
Weight $(\mathrm{Kg})$ & $55.6 \pm 5.3$ & $55.5 \pm 8.3$ & $57.1 \pm 8.0$ & $58.7 \pm 7.1$ & $56.8 \pm 5.9$ \\
Age $(\mathrm{y})$ & $23 \pm 1.1$ & $21.3 \pm 0.5$ & $23.1 \pm 1.0$ & $21.1 \pm 2.1$ & $21.1 \pm 0.9$ \\
Body mass index $\left(\mathrm{kg} / \mathrm{m}^{2}\right)$ & $20.5 \pm 1.2$ & $20.9 \pm 2.6$ & $20.6 \pm 2.4$ & $21.4 \pm 1.5$ & $20.1 \pm 0.9$ \\
\hline Data are mean $\pm \mathrm{SD}$. & & & & & \\
\hline
\end{tabular}

Table 2. Ethnic Comparisons in Pharmacokinetic Parameters (Mean \pm SD) in Healthy Subjects of Han, Mongolian, Korean, Hui, and Uighur descent after Administration of $1 \mathrm{~g}$ of Tinidazole $(\mathrm{N}=10)$.

\begin{tabular}{|c|c|c|c|c|c|}
\hline Parameters & Han & Mongolian & Korean & Hui & Uighur \\
\hline $\mathbf{C}_{\max }(\mu \mathrm{g} / \mathrm{mL})$ & $19.04 \pm 2.42$ & $19.22 \pm 4.93$ & $20.83 \pm 3.33$ & $20.25 \pm 4.05$ & $18.81 \pm 3.10$ \\
\hline $\mathbf{T}_{\max }(\mathrm{h})$ & $2.15 \pm 0.47$ & $2.20 \pm 0.59$ & $2.30 \pm 0.63$ & $2.10 \pm 0.66$ & $2.25 \pm 0.54$ \\
\hline $\mathbf{t}_{1 / 2}(\mathrm{~h})$ & $16.94 \pm 2.40$ & $16.39 \pm 1.79$ & $16.63 \pm 1.82$ & $16.81 \pm 1.56$ & $14.34 \pm 1.92^{*}$ \\
\hline $\operatorname{Ke}(1 / \mathrm{h})$ & $0.042 \pm 0.006$ & $0.043 \pm 0.005$ & $0.042 \pm 0.005$ & $0.042 \pm 0.004$ & $0.049 \pm 0.007^{*}$ \\
\hline $\mathbf{V d} / \mathbf{F}(\mathrm{L})$ & $51.01 \pm 9.49$ & $51.18 \pm 11.72$ & $47.52 \pm 7.64$ & $49.21 \pm 9.33$ & $53.63 \pm 8.68$ \\
\hline $\mathbf{C L} / \mathbf{F}(\mathrm{L} / \mathrm{h})$ & $2.09 \pm 0.29$ & $2.16 \pm 0.42$ & $1.98 \pm 0.22$ & $2.06 \pm 0.50$ & $2.59 \pm 0.24^{*}$ \\
\hline $\begin{array}{l}\mathbf{A U C}_{\mathbf{0 - t}} \\
(\mathrm{h} \cdot \mu \mathrm{g} / \mathrm{mL})\end{array}$ & $454.37 \pm 59.74$ & $444.93 \pm 82.19$ & $484.74 \pm 58.20$ & $483.51 \pm 116.83$ & $378.40 \pm 40.56^{*}$ \\
\hline $\begin{array}{l}\text { AUC }_{0 \text {-inf }} \\
(\mathrm{h} \cdot \mu \mathrm{g} / \mathrm{mL})\end{array}$ & $486.13 \pm 65.65$ & $479.70 \pm 99.74$ & $511.07 \pm 53.47$ & $514.25 \pm 130.78$ & $388.58 \pm 37.37^{*}$ \\
\hline $\begin{array}{l}\text { CL/F /weight } \\
(\mathrm{L} / \mathrm{h}) /(\mathrm{kg})\end{array}$ & $0.038 \pm 0.005$ & $0.039 \pm 0.004$ & $0.035 \pm 0.003$ & $0.034 \pm 0.005$ & $0.046 \pm 0.005^{*}$ \\
\hline $\begin{array}{c}\text { AUC }_{0 \text {-inf }} \text { (weight) } \\
(\mathrm{kg} \cdot \mathrm{h} \cdot \mu \mathrm{g} / \mathrm{mL})\end{array}$ & $26883 \pm 3252$ & $25997 \pm 2841$ & $28878 \pm 2750$ & $30221 \pm 3993$ & $21980 \pm 2289^{*}$ \\
\hline
\end{tabular}

*, $\mathrm{p}<0.05$ of the analysis of variance and Sheffe's multiple comparisons with the data of five nationalities.

\section{Safety}

No serious adverse effects were observed in all subjects during the study periods.

\section{DISCUSSION}

Pharmacokinetic parameters showed differences among Han, Mongolian, Korean, Hui, and Uighur 
healthy subjects after a single oral administration of $1 \mathrm{~g}$ of tinidazole. The $\mathrm{t}_{1 / 2}, \mathrm{AUC}_{0 \text {-inf }}, \mathrm{CL} / \mathrm{F}$ and $\mathrm{K}_{\mathrm{e}}$ values were significantly different between Uighur and other nationalities in China. The results indicate that the absorption of tinidazole showed no difference, while the metabolism of tinidazole significantly differed between Uighur subjects and those of other nationalities. The clearance of tinidazole in Uighur subjects was increased by $20 \%$ compared to those of other nationalities.

Several factors (height, weight, race, genetic polymorphisms in drug metabolism, etc.) may have contributed to the observed ethnic difference (20). However, no significant differences were found in the weight and height scores among these nationalities using examination of univariate analyses. The differences in pharmacokinetic parameters could not be explained by body weight in all subjects.

China is a multinational country that mainly includes Han, Mongolian, Korean, Hui, Uighur peoples. Han people, the largest nationality in China, have similar Asian characteristics to those of Mongolian, Korean, and Hui descent. In contrast, Uighur people share characteristics with Caucasians $(21,22)$. Within different racial groups, the metabolism of drugs may be influenced by polymorphisms of cytochrome enzymes. Tinidazole is metabolized primarily by the CYP3A4 isozyme (77\%) and to a lesser extent by CYP2B6 (12\%) (11, 12). Hepatic CYP3A activity has been shown to be lower in healthy Asian men compared with similar Caucasians (23), and that may result in the higher clearance and shorter elimination half-life in Uighur subjects than those of other nationalities. It is possible that some extrinsic factor may have caused the oral clearance in Uighur peoples to be higher (e.g. dietary differences). Pharmacokinetic differences can present between East Asians in inhibition of drug metabolism and response to different environmental inducers (24).

In conclusion, a significant differences in pharmacokinetic parameters was observed in Uighur subjects compared with other Chinese nationalities (Han, Mongolian, Korean, and Hui). Information on the concentration versus effect relationship of tinidazole is limited. It is acknowledged that the sample size in the study was small. Nevertheless, although this study showed some difference of tinidazole kinetics in Uighur people, it would seem unlikely that this difference is relevant clinically.

\section{ACKNOWLEDGMENTS}

This study was supported by a research grant from the 115 project of legionary medical treatment and public health. The authors acknowledge the Chifeng Clinical Department of 313th Hospital, the Pharmacy Department of 5th Hospital in Ningxia, the Pharmacy Department of Xinjiang Hospital, and the Medical Department of Yanbian University for providing the study conditions and helping to collect and select volunteers.

\section{REFERENCES}

1. Nord CE, Kager L. Tinidazole--microbiology, pharmacology and efficacy in anaerobic infections. Infection, 1983; 11: 54-60.

2. Gordts B, Hemelhof W, Asselman C, Butzler JP. In vitro susceptibilities of 25 Giardia lamblia isolates of human origin to six commonly used antiprotozoal agents. Antimicrob Agents Chemother, 1985; 28: 378-380.

3. Sears SD, O' Hare J. In vitro susceptibility of Trichomonas vagina is to 50 antimicrobial agents. Antimicrob Agents Chemother, 1988; 32: 144146.

4. Dhar KK, Dhall GI, Ayyagari A. Tinidazole prophylaxis in elective abdominal hysterectomy. IntJ Gynecol Obstet, 1993; 42: 121-125.

5. Karhunen M, Koskela O, Teisala K, Suikkari AM, Mattila J.: Prophylaxis and treatment of anaerobic infections following caesarean section with tinidazole. Chemotherapy, 1985; 31: 228-36.

6. Laitinen S, Ståhlberg M, Kairaluoma MI. Tinidazole prophylaxis in elective colorectal surgery. Scand J Gastroenterol, 1984; 19: 10271030.

7. Mitchell DA, Morris TA.: Tinidazole or pivampicillin in third molar surgery. Int $\mathrm{J}$ Oral Maxillofac Surg, 1987; 16: 171-174.

8. Wood BA, Faulkner JK, Monro AM. The pharmacokinetics, metabolism and tissue distribution of tinidazole. J Antimicrob Chemother, 1982; 10 (Suppl A): 43-57.

9. Viitanen J, Haataja H, Mannisto PT. Concentrations of metronidazole and tinidazole in male genital tissues. Antimicrob Agents Chemother, 1985; 28: 812-814.

10. Männistö P, Karhunen M, Mattila J, Koskela O, Suikkari AM, Heinonen P, Tuimala R, Haataja H. Concentrations of metronidazole and tinidazole in female reproductive organs after a single 
intravenous infusion and after repeated oral administration. Infection, 1984; 12: 197-201.

11. Li XQ, Bjorkman A, Andersson TB, Gustafsson LL, Masimirembwa CM. Identification of human cytochrome $\mathrm{P}(450)$ s that metabolise anti-parasitic drugs and predictions of in vivo drug hepatic clearance from in vitro data. EurJ Clin Pharmacol, 2003; 59: 429-442.

12. Wood SG, John BA, Chasseaud LF, Brodie RR, Baker JM, Faulkner JK, Wood BA, Darragh A, Lambe RF. Pharmacokinetics and metabolism of 14C-tinidazole in humans. J Antimicrob Chemother, 1986; 17: 801-809.

13. Li GC, Chen Y, Chen W, Wang YH. Study on the phenotype in the metabolic polymorphism of dextromethorphan in Han, Uighur, Hasake nationalities. Chin J Clin Pharmacol, 2004; 20: 104-108.

14. Li GC, Chen CY, Wang YH. Comparative pharmacokinetic study on ciprofloxacin in healthy volunteers of the Han, Uigur and Kazak nationalities. Chin J Clin Pharmacol, 1997; 13: 145-148.

15. He P, Liu GX, Liu ZH, Sun FY, Li CY, Yang Y. Ethnic differences in disposition of antipyrine and acetaminophen between Tibetan and Han healthy volunteers. Acta Pharmaceutica Sinica, 1994; 29: 566-569.

16. Chang XY, Xia DY, Guo T. Determination of contents of tinidazole in blood plasma by HPLC. Chin J Clin Pharm, 2007; 16: 382-384.
17. Chen ZY, Sun RY. DAS software for pharmacological calculation. Chin J Clin Pharmacol Therapeutics, 2002; 7: 562-564.

18. SPSS Inc. SPSS Base User Guide 11.0. Chicago Illinois SPSS Inc, 2001.

19. Liu QG, Zhang FL. Application of SPSS in medical science. Inner Mongolia University Publishing House, 2002; 9: 75-80.

20. Johnson JA. Predictability of the effects of race or ethnicity on pharmacokinetics of drugs. Int J Clin Pharmacol Ther, 2000; 38: 53-60.

21. Yu MS, Qiu XF, Xue JL, Liu ZD, Tan JZ, Li HJ, Liu DX, Li L, Yu WZ, Tang XZ, Zhou MR. Study on the mtDNA polymorphism in Han, Urghur, Hasake and Hui nationalities. Science in China, Ser.B, 1988; 18: 60-70.

22. ao TM, Zhang GL, Yuan YD, Du RF. Genetic distances estimated on the basis of HLA. Acta Anthropoloqica Sinica, 1984; 3: 166-169.

23. teishi T,Watanabe M, Nakura H, Asoh M, Shirai H, Mizorogi Y. CYP3A activity in European American and Japanese men using midazolam as an in vivo probe. Clin Pharmacol Ther, 2001; 69: 333-339.

24. M.K, Johnson JA, Derendorf H. Differences in drug pharmacokinetics between East Asians and Caucasians and the role of genetic polymorphisms. J Clin Pharmacol, 2004; 44: 1083-1105. 